\title{
Double whammy: sex-related headache and amnesia
}

\author{
B. Ziso ${ }^{1}$ - A. J. Larner ${ }^{1}$ (]
}

Received: 23 October 2018 / Accepted: 19 March 2019 / Published online: 30 March 2019

(c) Belgian Neurological Society 2019

\section{Dear Editor,}

Recognised acute neurological consequences of sexual activity include amnesia, specifically the syndrome of transient global amnesia (TGA), and headache, specifically the syndrome of primary headache associated with sexual activity (PHSA) [1]. However, concurrence of both has not, to our knowledge, been previously reported.

A lady in her 50s and her husband reported that she suddenly developed a severe bilateral occipital headache with nausea during sexual activity, not associated with vomiting or loss of consciousness. After intercourse, her husband noted that his wife was vague, confused, and asking repeated questions, such as whether she had had a shower; this had in fact occurred before intercourse. She was unfamiliar with events which had occurred in the few weeks prior to this, such as buying new household furniture. Matters settled after an hour or so, but she had no recollection of the shower, sex, or its immediate aftermath. By the time she was seen in a cognitive disorder clinic about 3 weeks later, her performance on cognitive screening instruments (MiniAddenbrooke's Cognitive Examination, Free-Cog) was normal. Brain imaging (CT) undertaken a few days after the event, because of concern about a possible stroke, was also normal.

This lady fulfilled suggested diagnostic criteria for TGA, with an eyewitness account of both anterograde and retrograde amnesia [2], which occurred in temporal association with two recognised precipitating factors for TGA, namely water contact and sexual activity [3]. The headache had features in keeping with PHSA, although as a single event it failed one of the criteria stipulated by the International Classification of Headache Disorders [4]. Although a possible association between migraine and TGA is recognised,

A. J. Larner

a.larner@thewaltoncentre.nhs.uk

1 Walton Centre for Neurology and Neurosurgery, Lower Lane, Fazakerley, Liverpool L9 7LJ, UK at both clinical and aetiological levels, this patient had no prior personal history of migraine, and there was no family history of either migraine or TGA [5].

Whether TGA and PHSA are entirely separate entities or are pathophysiologically related conditions is not currently known [1]. This case suggests the possibility of shared pathophysiology, at least in this patient. Studies of PHSA might shed light on the vexed question of the pathogenesis of TGA.

Funding This study was not funded.

\section{Compliance with ethical standards}

Conflict of interest The authors have no conflicts of interest to disclose.

Ethical approval All procedures performed in studies involving human participants were in accordance with the ethical standards of the institutional and/or national research committee and with the 1964 Helsinki declaration and its later amendments or comparable ethical standards.

Informed consent Informed consent was obtained from all individual participants included in the study.

\section{References}

1. Larner AJ (2008) Transient acute neurologic sequelae of sexual activity: headache and amnesia. J Sex Med 5:284-288

2. Hodges JR, Warlow CP (1990) Syndromes of transient amnesia: towards a classification. A study of 153 cases. J Neurol Neurosurg Psychiatry 53:834-843

3. Larner AJ (2017) Transient global amnesia. From patient encounter to clinical neuroscience. Springer, London

4. Headache Classification Committee of the International Headache Society (IHS) (2013) The international classification of headache disorders, 3rd edition (beta version). Cephalalgia 33:629-808

5. Larner AJ (2017) Recurrent transient global amnesia: is there a link to familial history? Prog Neurol Psychiatry 21(4):17-19

Publisher's Note Springer Nature remains neutral with regard to jurisdictional claims in published maps and institutional affiliations. 